\title{
Fahrenheit 451
}

\section{Erhard Taverna}

Dr. med., Mitglied der Redaktion

Die Temperatur, bei der Papier zu brennen beginnt. Ray Bradbury (1920-2012) schrieb in den 1950er Jahren seine Geschichte The Fireman, die der Film von Truffaut mit dem Titel Fahrenheit 451 einem grösseren Publikum bekannt machte. Bücher zu lesen oder zu besitzen ist verboten. Was noch übrig ist, wird verbrannt. Lesen ist elitär und untergräbt die Chancengleichheit. Für Ersatz sorgt eine ausgefeilte Unterhaltungsindustrie.

Seit 1995 erinnert am 23. April die UNESCO mit einem Welttag des Buches an die Bedeutung des Lesens von Büchern. Der Buchhandel ruft sich mit Sonderaktionen in Erinnerung. Ein Rückzugsgefecht, denn zumindest in Deutschland ist der Buchverkauf in den letzten zehn Jahren um über einen Viertel gesunken. Am Preis kann es nicht liegen, denn Bücher sind billiger geworden. Die Entwicklung verteilt sich sehr

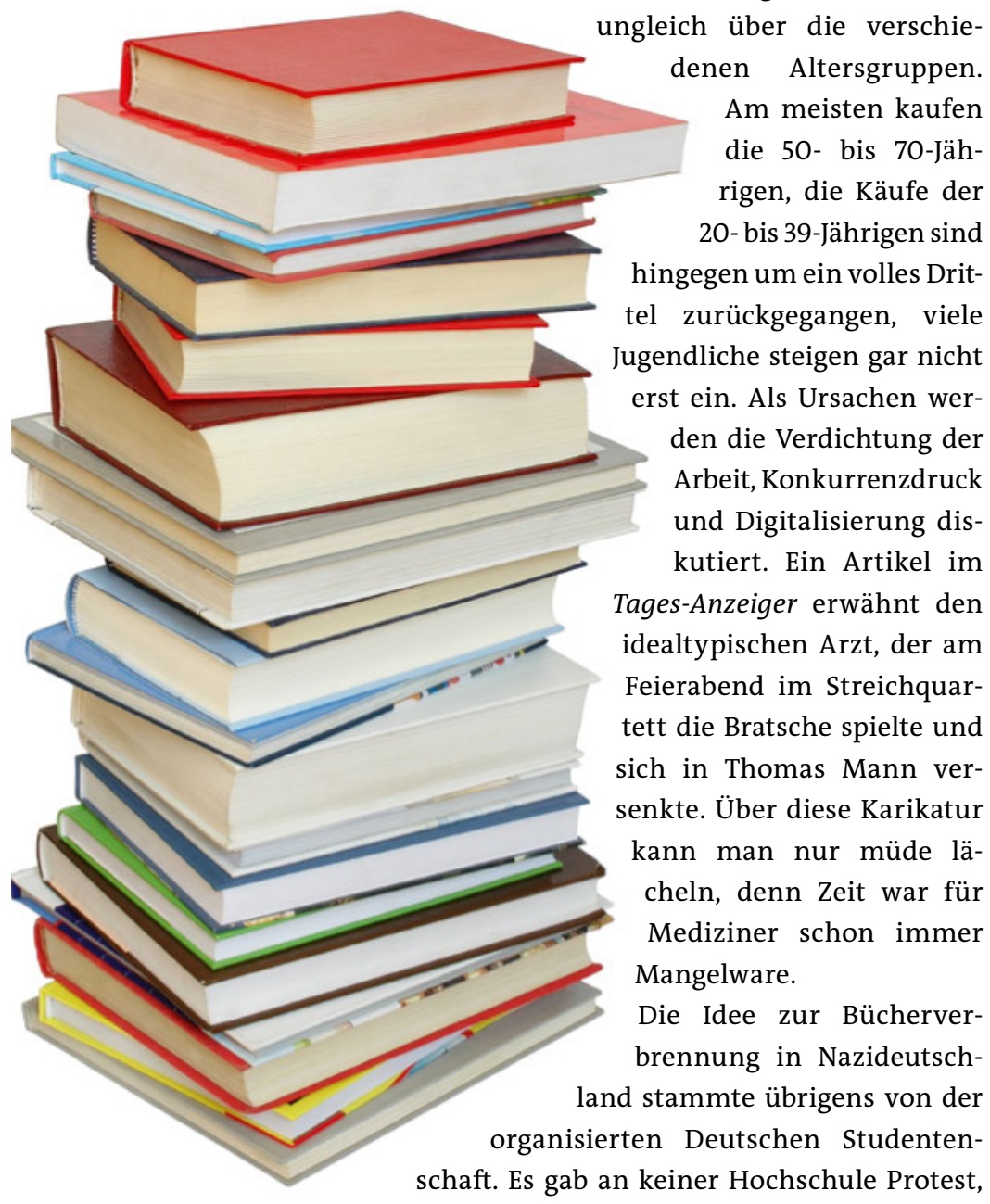

weder von Studenten noch von Professoren. Ein arbeitsloser Bibliothekar erstellte die ersten schwarzen Listen. Ein grotesker Gegensatz dazu war die Gottbegnadeten-Liste. Vom Kriegsdienst freigestellte Künstler, darunter auch Schriftsteller, wurden als unverzichtbar für das NS-Regime eingestuft. Nirgends haben Bücher mehr Bedeutung als in Diktaturen. Ausgerechnet in der DDR wurde jährlich mit einem Tag des freien Buches an die Säuberungsaktionen erinnert. Mit Papierentzug und Zensur verfügten die neuen Machthaber über subtilere Methoden. Der wiederauferstandene Börsenverein des deutschen Buchhandels konterte in der Bundesrepublik ab 1983 mit seinem Tag des Buches. Zeitzeugen berichten, dass zu Sowjetzeiten viel mehr gelesen wurde als heute. Klassiker und natürlich die Untergrundschriften der Dissidenten. Die SamisdatLiteratur umging das staatlich kontrollierte Verlagswesen. Wer konnte, publizierte illegal im Westen.

Interessant an Ray Bradburys Kurzgeschichte ist, dass eine Volksmehrheit schrittweise die Abschaffung der Bücher einforderte. Das erinnert an die endlosen Bildungsdiskussionen unserer Tage, wo unter anderem der Spiegel in einer Titelgeschichte, «Wie Bildung endlich gelingt», betonte, dass Digitalisierung, Chancengleichheit, Inklusion, Ganztagesschule und gutes Essen wichtig seien. Angehende Lehrer müssten von dem Fach, das sie unterrichten, nicht unbedingt viel verstehen, Hauptsache, sie seien sozial kompetent. Nichtleser seien nicht demokratiefähig, tönt es von einer anderen Seite. Bücher vermitteln Fantasie, Konzentration, Kritikfähigkeit, Wissen und Empathie. Man könnte das ergänzen und sagen, dass Bücher auch Lebensabschnitte und Interessen verkörpern. Unterstrichene Textstellen, geknickte Ecken, ein Exlibris, das Datum eines Kaufortes, private Widmungen, Randnotizen, eingeschobene Zeitungsabschnitte, ein geschenktes Lesezeichen oder geflickte Einbände tragen bei zu einer papiergewordenen Biographie. Am Lebensende stehen sie dann aufgereiht auf Regalen, vielstimmige Erinnerungen, gewachsen wie die Jahresringe eines Leserbaums. Dann finden sie ihre Erben oder sie landen in der Mulde. Habent fata sua libelli, Bücher haben ihre Schicksale, befand schon der römische Lateiner.

Bildnachweis

(c) Atman | Dreamstime.com 